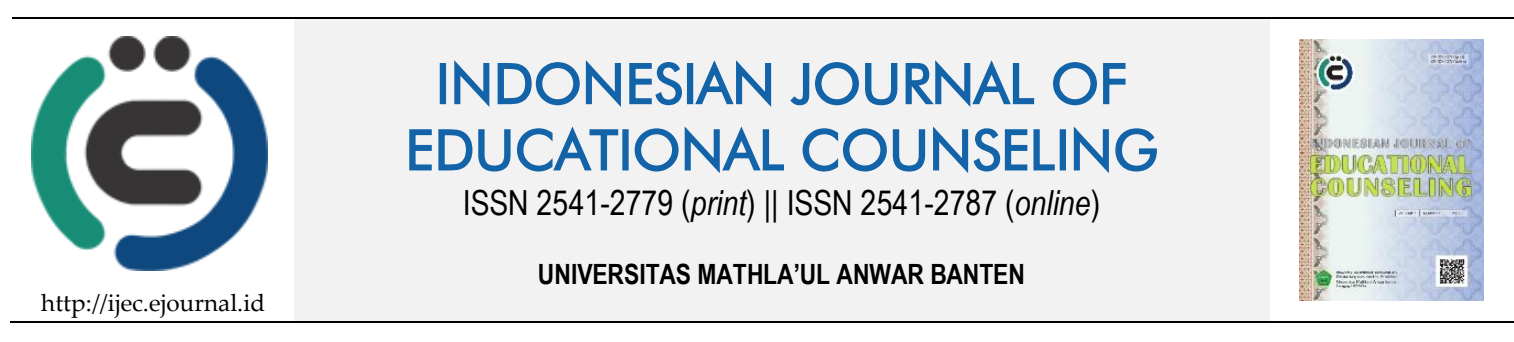

Research Based Article

\title{
Pengaruh Gaya Kepemimpinan Transformasional dan \\ Sarana Prasarana terhadap Budaya Kerja Guru Sekolah Dasar Gugus 4 Parungsari di Kecamatan Sajira Kabupaten Lebak
}

\author{
Tetei Rostiawati ${ }^{1}$, Amalia Sapriati ${ }^{2}$, Tita Rosita $^{2}$ \\ 1,2 Universitas Terbuka, Indonesia
}

\begin{tabular}{ll}
\hline Article History & ABSTRACT \\
\hline Received: 03.06.2021 & THE EFFECT OF TRANSFORMATIONAL LEADERSHIP STYLE AND \\
Received in revised form: & INFRASTRUCTURE ON THE WORK CULTURE OF TEACHERS IN \\
01.07 .2021 & ELEMENTARY SCHOOL OF GROUP 4 PARUNGSARI IN SAJIRA SUB- \\
Accepted: 08.07.2021 & DISTRICT, LEBAK REGENCY. Work culture in schools is closely related to \\
Available online: 30.07 .2021 & leadership style and facilities and infrastructure. In this case, the low work \\
& culture of elementary school teachers is also commonly found in elementary \\
& school teachers in Cluster 4 Parungsari, Sajira District, Lebak Regency. Based \\
& on data from the Sajira District education office, it was recorded that 52 teachers \\
& or 50\% (104 teachers from 12 elementary schools) found a low work culture as \\
& indicated by the number of teachers who came late to school, the learning \\
& process in the classroom did not match the time allocation, and the teacher's \\
& lack of creativity in creating innovative learning. This is quite interesting to be \\
& studied and analyzed further. The purpose of this study is to analyze the \\
& influence of transformational leadership style and infrastructure on the work \\
& culture of teachers. This research is quantitative research with Explanatory \\
& Survey method. The sample used was 100 elementary school teachers in the \\
& Parungsari Village, Group 4, Sajira District, Lebak Regency. Data was collected \\
& using questionnaire/questionnaire. The research results obtained are: 1 ) There \\
& is an influence of Transformational Leadership Style on Teacher Work Culture; \\
& 2) There is an influence of Facilities and Infrastructure on the Teacher's Work \\
& Culture; 3) There is an influence of Transformational Leadership Style and \\
Infrastructure on Teacher Work Culture.
\end{tabular}

KEYWORDS: Infrastructure, Teacher Work Culture, Transformational Leadership Style.

DOI: 10.30653/001.202152.182

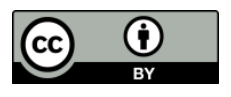

This is an open access article distributed under the terms of the Creative Commons Attribution 4.0 International License, which permits unrestricted use, distribution, and reproduction in any medium, provided the original work is properly cited. (c) 2021 Tetei Rostiawati, Amalia Sapriati, Tita Rosita.

\footnotetext{
${ }^{1}$ Corresponding author's address: Jl. Pd. Cabe Raya, Pd. Cabe Udik, Kec. Ciputat, Kota Tangerang Selatan, Banten 15418, Indonesia. E-mail: tita@ecampus.ut.ac.id
} 


\section{PENDAHULUAN}

Perkembangan zaman yang semakin pesat menuntut sebuah sekolah untuk dapat mengembangkan dan memaksimalkan faktor-faktor internal dalam sekolah seperti sumber daya manusia, pemimpin sekolah, motivasi kerja, sarana prasarana, dan budaya kerja guru. Hal ini penting untuk membangun pondasi sekolah agar dapat menghasilkan sumber daya manusia yang berkualitas dan berdaya saing. Kepala sekolah pada hakikatnya adalah guru yang memiliki tugas tambahan dalam memimpin sebuah sekolah. Kepala sekolah merupakan komponen pendidikan yang paling berperan dalam meningkatkan kualitas pendidikan (Mukhtar, 2015). Peraturan Menteri Pendidikan Nasional Nomor 13 Tahun 2007 tentang Standar Kepala Sekolah/ Madrasah, disebutkan bahwa kepala sekolah mengelola guru dan staf dalam rangka pendayagunaan sumber daya manusia secara optimal serta menciptakan budaya dan iklim sekolah yang kondusif dan inovatif bagi pembelajaran melalui kompetensi kepribadian yang ditampilkan kepala sekolah sebagai pribadi yang bertanggungjawab, kreatif, dan memiliki motivasi. Gaya kepemimpinan dalam sekolah dikatakan baik apabila tujuan sekolah dikomunikasikan terlebih dahulu pada guru, karena seorang kepala sekolah sangat berpengaruh terhadap keberhasilan sekolah dalam mencapai tujuan.

Kepemimpinan transformasional merupakan pemimpin yang menginspirasi para pengikut untuk melampaui kepentingan pribadi mereka yang mampu membawa dampak mendalam dan luar biasa pada para pengikut (Robbins \& Timothy, 2010: 472). Gaya kepemimpinan transformasional memiliki hubungan yang lebih intens antara kepala sekolah dan guru. Hubungan tersebut dapat mempengaruhi guru agar mampu menjalankan perintah dengan senang hati dan tanpa paksaan. Kepemimpinan transformasional ditunjukkan dengan memberikan perhatian individual. Kepala sekolah dapat memberikan tugas kepada guru sesuai dengan kemampuan serta mampu menerapkan stimulasi intelektual seperti bagaimana cara menganalisis suatu situasi dan bagaimana cara agar guru dapat mengembangkanya secara kreatif (Septyan, 2017). Hal ini sejalan dengan pendapat Yuki (2010:305) bahwa kepemimpinan transformasional mempunyai empat dimensi, yaitu karismatik, motivasi yang menginspirasi, stimulasi intelektual, dan perhatian secara individual.

Sebagai institusi penyelenggaraan pendidikan, sekolah terbentuk oleh budaya kerja. Budaya kerja di sekolah dipengaruhi oleh gaya kepemimpinan serta sarana dan prasarana. Dengan begitu, optimalnya suatu sekolah dalam menjalankan tugasnya sangat ditentukan oleh budaya kerja para guru di dalamnya. Budaya kerja rendah pada guru dapat dilihat dari perilakunya yang terlihat tidak disiplin. Hal ini sesuai dengan data Badan Kepegawaian Pendidikan dan Pelatihan (BKPP) Kabupaten Lebak bahwa Pegawai Negeri Sipil (PNS) tercatat sedikitnya 50 abdi negara bolos atau mangkir lebih dari lima hari (https://bantenhits.com). Guru sebagai Aparatur Sipil Negara (ASN) sebaiknya memiliki budaya kerja yang baik guna mendukung pembangunan berkelanjutan. Berdasarkan hasil penelitian, Lie, et all. (2019) berpendapat bahwa fenomena terkait budaya kerja guru juga terjadi pada guru swasta Sultan Agung Pematangsiantar. Guru tidak bertanggungjawab menjalankan tugasnya, banyaknya tugas yang tidak dikerjakan dengan tepat waktu, dan belum bekerja dengan penuh integritas demi kemajuan sekolah.

Budaya kerja rendah pada guru SD juga banyak ditemukan pada guru Sekolah Dasar Gugus 4 Parungsari Kecamatan Sajira Kabupaten Lebak. Berdasarkan data dinas pendidikan Kecamatan Sajira tercatat 52 guru atau 50 \% (104 guru dari 12 SD) banyak ditemukan budaya kerja rendah yang terindikasi dari banyaknya guru yang datang 
terlambat ke sekolah, proses pembelajaran di kelas tidak sesuai alokasi waktu, dan kurang kreatifnya guru dalam menciptakan pembelajaran yang inovatif. Hal ini sudah membudaya atau menjadi tradisi di kalangan guru SD Gugus 4 Parungsari Kecamatan Sajira Kabupaten Lebak. Selain itu, budaya kerja guru rendah dibuktikan dengan gaya kepemimpinan dan sarana prasarana yang belum memotivasi dan memfasilitasi guru untuk meningkatkan budaya kerja yang baik. Budaya kerja guru sangat ditentukan oleh kondisi internal organisasi yaitu gaya kepemimpinan kepala sekolah serta sarana prasarana. Gaya kepemimpinan transformasional yang dibiasakan serta sarana prasarana yang optimal mampu mendorong budaya kerja sebagai sebuah kebutuhan untuk mencapai tujuan yang ingin dicapai bersama.

Berdasarkan latar belakang yang telah dipaparkan, maka penelitian ini mengkaji dan menganalisis secara komprehensif terkait gaya kepemimpinan tranformasional dan sarana prasarana terhadap budaya kerja guru-guru SD di Gugus 4 Parungsari Kecamatan Sajira Kabupaten Lebak.

\section{METODE}

Metode penelitian dengan menggunakan penelitian kuantitatif dengan metode Survey Explanatory. Survey Explanatory merupakan metode yang menjelaskan hubungan kausal antara variabel-variabel yang diteliti melalui pengujian hipotesis, melalui pengambilan sampel dari satu populasi, dan menggunakan kuesioner sebagai alat pengumpulan data yang pokok (Singarimbun \& Effendi, 2003:3). Dalam penyusunan instrumen atau alat pengumpul data, variabel yang menjadi acuan dalam menyusun angket yaitu tentang gaya kepemimpinan transformasional, sarana prasarana, dan budaya kerja. Adapun cara yang digunakan dalam melakukan analisis data yaitu menggunakan analisis regresi berganda dan analisis korelasi.

Dalam penelitian ini, populasi dan sampel yang digunakan sebagai objek penelitian adalah dewan guru Sekolah Dasar di wilayah Desa Parungsari Gugus 4 Kecamatan Sajira Kabupaten Lebak sebanyak 100 orang guru.

\section{HASIL DAN PEMBAHASAN}

\section{Pengaruh Gaya Kepemimpinan Tranformasional terhadap Budaya Kerja Guru}

Berdasarkan pada rumusan masalah dapat diketahui bahwa terdapat pengaruh Gaya Kepemimpinan Transformasional terhadap Budaya Kerja Guru, yang dapat diperoleh thitung lebih besar dari nilai tabel atau nilai thitung (11.273) $>$ tabel (1.98498) dan didapat nilai signifikansi lebih kecil daripada nilai probabilitas 0,05 atau nilai $0,000<0,05$. Maka, dapat disimpulkan Gaya Kepemimpinan Transformasional (X1) memiliki pengaruh terhadap Budaya Kerja Guru SD Gugus 4 Parungsari (Y).

Hal ini sesuai dengan penelitian terdahulu yang dilakukan oleh Ismail \& Mydin (2018) yang menyatakan bahwa Gaya Kepemimpinan Transformasional dapat memberikan pengaruh dalam meningkatkan budaya kerja guru yang dalam hal ini ditunjukkan dalam peningkatan perilaku inovatif guru. Selain itu, berdasarkan hasil penelitian terdahulu dari Jabeen, A., Zia-Ul-Islam, S., \& Khan, A. (2020) dan Azizah, N.Y, et al (2020) mengungkapkan bahwa Gaya Kepemimpinan Transformasional memiliki hubungan atau pengaruh yang positif dan signifikan terhadap budaya kerja guru yang ditunjukkan pada prestasi kerja dan kepuasan responden. 
Gaya Kepemimpinan transformasional dianggap sebagai gaya kepemimpinan yang paling efektif. Saat Gaya Kepemimpinan Tranformasional ditingkatkan maka dapat dijadikan sebagai ukuran bahwa budaya kerja guru dapat dipengaruhi dan ditingkatkan pula. Money (2017) mengungkapkan bahwa satu-satunya cara terbesar untuk mempengaruhi sebuah organisasi adalah dengan fokus pada Kepemimpinan Transformasional. Pemimpin transformasional adalah pemimpin yang mampu merangsang dan menginspirasi pengikut untuk mencapai hasil yang luar biasa dan dalam prosesnya mengembangkan kapasitas kepemimpinan mereka sendiri. Kepemimpinan transformasional melibatkan perubahan bukan hanya terjadi di sekolah atau bangsa tetapi terjadi pada orang. Melalui kekuatan visi dan kepribadiannya, pemimpin transformasional mampu menginspirasi pengikut untuk mengubah ekspektasi, persepsi dan motivasi untuk bekerja menuju tujuan bersama.

Dari hasil pengumpulan data dalam penelitian ini dapat dikatakan bahwa gaya kepemimpinan transformasional berpengaruh positif pada kinerja tim dan untuk setiap tingkat organisasi (Wang et al, 2011). Dalam hal ini, pemimpin transformasional juga memotivasi dan menginspirasi bagi pengikut untuk mencapai kinerja di luar ekspektasi dengan mengubah sikap, keyakinan, dan nilai-nilai para pengikut mereka (Abdullah, 2018; Rafferty \& Griffin, 2004; Krisnanda \& Surya, 2019). Selain itu, terdapat hubungan tidak langsung antara gaya kepemimpinan dan kinerja bawahan yang dimediasi oleh budaya organisasi (Sinaga, Asmawi, Madhakomala, \& Suratman, 2018), lingkungan kerja (Imran, Fatima, Zaheer, Yousaf, \& Batool, 2012), keterlibatan karyawan (Buil, Martínez, \& Matute, 2019; Hee, Ibrahim, Kowang, \& Fei, 2018; Schmitt, Den Hartog, \& Belschak, 2016), dan motivasi kerja (Manik, 2016; Mavhungu \& Bussin, 2017).

Kepemimpinan transformasional secara signifikan dan positif terkait dengan prestasi kerja guru. Pada bidang pendidikan, kepemimpinan transformasional terbukti sebagai pendekatan yang positif terhadap prestasi kerja karyawan. Kepemimpinan transformasional dianggap sebagai gaya kepemimpinan yang paling efektif. Kepemimpinan transformasional secara positif meningkatkan kinerja karyawan (Jabeen, Zia-Ul-Islam, \& Khan, 2020). Azizah, et al (2020) mengatakan bahwa kepemimpinan transformasional mengikat pemimpin dan bawahan dalam proses kolaboratif agar dapat berkontribusi pada kinerja seluruh organisasi.

Aboramandan \& Kundi (2020) berpendapat bahwa seorang pemimpin transformasional menjauhkan pengikut mereka dari kepentingan pribadi langsung mereka dengan memberikan perhatian individu, merangsang mereka secara intelektual, menginspirasi mereka, dan menggunakan pengaruh ideal. Conger et al. (2000) berpendapat bahwa kepemimpinan transformasional membuat pengikutnya berperilaku lebih dewasa dan idealis, menunjukkan kepedulian yang lebih besar untuk mencapai tujuan, aktualisasi diri, dan kebutuhan sesama pekerja, organisasi mereka, dan masyarakat secara keseluruhan.

Money (2017) mengungkapkan bahwa satu-satunya cara terbesar untuk mempengaruhi sebuah organisasi adalah dengan fokus pada Kepemimpinan Transformasional. Pemimpin transformasional adalah pemimpin yang mampu merangsang dan menginspirasi pengikut untuk mencapai hasil yang luar biasa dan dalam prosesnya mengembangkan kapasitas kepemimpinan mereka sendiri. Kepemimpinan transformasional melibatkan perubahan bukan hanya terjadi di sekolah atau bangsa tetapi terjadi pada orang. Melalui kekuatan visi dan kepribadiannya, pemimpin 
transformasional mampu menginspirasi pengikut untuk mengubah ekspektasi, persepsi dan motivasi untuk bekerja menuju tujuan bersama.

\section{Pengaruh Sarana dan Prasarana terhadap Budaya Kerja Guru}

Berdasarkan pada rumusan masalah dapat diketahui bahwa terdapat pengaruh Sarana dan Prasarana terhadap Budaya Kerja Guru, yang dapat diperoleh thitung lebih besar dari nilai tabel atau nilai thitung (4.325) $>$ tabel (1.98498) dan didapat nilai signifikansi lebih kecil daripada nilai probabilitas 0,05 atau nilai $0,000<0,05$. Maka, dapat disimpulkan bahwa terdapat pengaruh Sarana dan Prasarana (X2) terhadap Budaya Kerja Guru SD Gugus 4 Parungsari (Y). Hal ini sesuai dengan penelitian terdahulu yang dikemukakan oleh Fauziana, D. (2017) bahwa hasil penelitiannya menunjukkan sebagai berikut:

1) Pengaruh positif dan signifikan sarana prasarana terhadap kinerja guru di Pondok Pesantren Al-Islam.

2) Terdapat pengaruh positif dan signifikan lingkungan kerja terhadap kinerja guru di Pondok Pesantren Al-Islam.

3) Terdapat pengaruh positif dan signifikan secara bersama-sama sarana prasarana dan lingkungan kerja terhadap kinerja guru di Pondok Pesantren Al-Islam.

Sarana dan prasarana ini merupakan peralatan yang secara langsung digunakan dalam proses pembelajaran untuk mencapai tujuan seperti ruang dan buku, sedangkan prasarana adalah peralatan yang secara tidak langsung digunakan dalam proses pembelajaran untuk mencapai tujuan seperti bangunan sekolah, lapangan olahraga, dan lain sebagainya (Suhelayanti, Aziz, Sari, Safitri, Saputra, Purba, Revida, Purba, Muharlisiani, \& Simarmata, 2020; Suranto, 2019; Usman \& Murniati, 2019).

Dalam Peraturan Pemerintah Nomor 19 Tahun 2005 tentang Standar Nasional Pendidikan Bab VII Pasal 42 disebutkan bahwa sarana yang wajib dimiliki oleh setiap satuan pendidikan meliputi 1) perabot; 2) peralatan pendidikan;3) media pendidikan; 4) buku dan sumber belajar lain; 5) bahan habis pakai; serta 6) perlengkapan lain yang diperlukan guna menunjang proses pembelajaran yang teratur dan berkelanjutan. Sementara prasarana yang wajib dimiliki oleh setiap satuan pendidikan meliputi 1) lahan; 2) ruang kelas; 3) ruang pimpinan satuan pendidikan; 4) ruang pendidik; 5) ruang tata usaha; 6) ruang perpustakaan; 7) ruang laboratorium; 8) ruang bengkel kerja; 9) ruang unit produksi; 10) ruang kantin; 11) instalasi daya dan jasa; 12) tempat berolahraga; 13) tempat beribadah; 14) tempat bermain; 15) tempat berkreasi; dan 16) ruang atau tempat lain yang diperlukan guna menunjang proses pembelajaran yang teratur dan berkelanjutan.

Adapun berdasarkan Peraturan Menteri Pendidikan Nasional Nomor 24 Tahun 2007 tentang Standar Sarana dan Prasarana Sekolah/Madrasah Pendidikan Umum, sekurangkurangnya sebuah SD/MI memiliki prasarana sebagai berikut. 1) ruang kelas; 2) ruang perpustakaan; 3) laboratorium IPA; 4) ruang pimpinan; 5) ruang guru; 6) tempat beribadah; 7) ruang UKS; 8) kamar mandi; 9) gudang; 10) ruang sirkulasi; 11) tempat bermain atau berolahraga. Segala sesuatu yang berkaitan dengan pengelolaan dan pemanfaatan sarana prasarana di lingkungan sekolah diatur dalam peraturan menteri tersebut.

Kondisi sarana prasarana serta optimalisasi pengelolaan dan pemanfaatan sarana prasarana di sekolah akan mempengaruhi keberhasilan program pendidikan (Matin \& Fuad, 2016). Tanpa adanya sarana prasarana yang memadai, pendidikan tidak akan bisa berjalan dengan baik (Suhelayanti dkk, 2020). Prosedur dan sistem pengelolaan yang 
tidak jelas serta tidak sesuainya kemauan dan kemampuan pengelolaan sarana prasarana akan meruntuhkan program pembelajaran yang sedang dijalankan. Maka dari itu, kepedulian warga sekolah (mulai dari kepala sekolah, guru, tenaga administrasi, sampai staf lainnya) terhadap pengelolaan dan pemanfaatan sarana prasarana merupakan hal penting yang harus diperhatikan agar sarana prasarana yang dibutuhkan sekolah berfungsi secara optimal dalam menunjang proses pembelajaran.

Warga sekolah sebaiknya memahami serta mampu mengelola secara profesional sarana prasarana yang dimiliki oleh sekolah. Hal tersebut relevan dengan kebijakan menurut Kemdikbud tentang standar kompetensi yang harus dimiliki warga sekolah, salah satunya ialah kompetensi manajerial kepala sekolah yang harus memiliki kemampuan mengelola sarana prasarana sekolah sebagai bentuk pendayagunaan secara optimal (Matin \& Fuad, 2016).

\section{Pengaruh Gaya Kepemimpian Transformasional dan Sarana Prasarana terhadap Budaya Kerja Guru}

Berdasarkan hasil penelitian pada rumusan masalah dapat ditemukan bahwa pengaruh Gaya Kepemimpinan Transformasional dan Sarana Prasarana terhadap Budaya Kerja Guru dapat diperoleh Fhitung untuk model regresi linear yang digunakan sebesar 120,399, untuk memperoleh $\mathrm{F}_{\text {tabel }}$ dengan tingkat keyakinan 95\%, a = 5\% dkl (3-1) = 2, dan dk2 (100-3) =97. Hasil diperoleh untuk Ftabel sebesar 3,09. Selanjutnya, ketentuan bila Fhitung $<$ Ftabel maka Ho diterima dan Ha ditolak, sebaliknya bila Fhitung $>F_{\text {tabel }}$ maka Ho ditolak dan Ha diterima. Hasil pengujian menunjukkan bahwa Fhitung $(146.192)>F_{\text {tabel }}(3,09)$ artinya terdapat pengaruh secara signifikan Gaya Kepemimpinan Transformasional dan Sarana Prasarana terhadap Budaya Kerja Guru.

Budaya kerja ini merupakan seperangkat asumsi, nilai dan norma yang dikembangkan dalam suatu organisasi sebagai pedoman tingkah laku anggota guna mengatasi berbagai permasalahan baik internal maupun eksternal (Wahyuningsih dkk, 2018). Salam, Ma'ufur, \& Laeli (2017) menggabungkan kedua pengertian mengenai budaya kerja tersebut menjadi suatu nilai, keyakinan, moral, norma, serta etika yang dilakukan oleh guru dalam melaksanakan tugasnya sehingga menjadi kebiasaan. Nilainilai yang diyakini serta perilaku manusia yang menjadi kebiasaan akan mempengaruhi keberhasilan kerja. Nilai-nilai yang dimaksud terbentuk dari agama, adat istiadat, dan norma yang menjadi keyakinan pada diri pekerja atau organisasi. Nilai-nilai yang menjadi kebiasaan tersebut merupakan budaya kerja.

Tentunya, lingkungan yang berbeda akan menghasilkan budaya kerja yang berbeda pula. Dalam lingkungan yang berbudaya tinggi terdapat suatu kesepakatan yang tinggi dari para anggotanya guna mempertahankan apa yang diyakini benar dari berbagai aspek yang akhirnya dapat membentuk keutuhan, loyalitas, serta komitmen perusahaan. Kesepakatan ini turun dari satu generasi ke generasi selanjutnya. Dari hal tersebut, dapat diketahui bahwa budaya kerja dapat mengubah sikap dan perilaku individu sebagai SDM dalam meningkatkan produktivitas kerja untuk menghadapi berbagai rintangan di masa depan. Budaya kerja yang baik dapat meningkatkan komunikasi yang lebih baik, jiwa gotong royong, kekeluargaan, kebersamaan, dan keterbukaan satu dengan lainnya. 


\section{SIMPULAN}

Terdapat pengaruh Gaya Kepemimpinan Transformasional, sarana dan prasarana, serta gaya kepemimpinan transformasional terhadap Budaya Kerja Guru. Namun demikian, Gaya Kepemimpinan Transformasional dan Sarana Prasarana harus selalu ditingkatkan agar dapat meningkatkan Budaya Kerja Guru yang lebih baik sehingga dapat senantiasa mengoptimalkan setiap aktivitas dan profesionalisme dalam bekerja. Agar dapat memperoleh hasil studi yang lebih baik, maka perlu dilakukan pengujian lagi berkaitan dengan faktor-faktor lain yang dapat mempengaruhi Budaya Kerja Guru dengan menambahkan variabel-variabel lainnya.

\section{REFERENSI}

Abdullah, E. (2018). Transformational leadership, technical competencies and self-efficacy on employee performance (A subsidiary of Dana Pensiun Bank Mandiri Empat-DPBME). Jurnal Manajemen, 9(1), 12-22.

Aboramadan, M., \& Kundi, Y. M. (2020). Does transformational leadership better predict workrelated outcomes than transactional leadership in the NPO context? Evidence from Italy. Voluntas: International Journal of Voluntary and Nonprofit Organizations, 31(6), 1254-1267.

Azizah, N. Y., et al. (2020). Transformational or Transactional Leadership Style: Which Affects Work Satisfaction and Performance of Islamic University Lecturers During COVID-19 Pandemi?. Systematic Reviews in Pharmacy, 11(7), 577-588.

Buil, I., Martínez, E., \& Matute, J. (2019). Transformational leadership and employee performance: The role of identification, engagement and proactive personality. International Journal of Hospitality Management, 77, 64-75.

Conger, J. A., Kanungo, R. N., \& Menon, S. T. (2000). Charismatic leadership and follower effects. Journal of Organizational Behavior, 21(7), 747-767.

Hee, O. C., Ibrahim, R., Kowang, T. O., \& Fei, G. C. (2018). Employee engagement as a mediator between transformational leadership and employee performance. Asian Journal of Scientific Research, 11(3), 441-448.

Imran, R., Fatima, A., Zaheer, A., Yousaf, I., \& Batool, I. (2012). How to boost employee performance: investigating the influence of transformational leadership and work environment in a Pakistani perspective. Middle-East Journal of Scientific Research, 11(10), 1455-1462.

Jabeen, A., Zia-Ul-Islam, S., \& Khan, A. (2020). Exploring Transformational Leadership Practices and Teachers' Job Performance in Higher Education Department. Global Educational Studies Review, $5(3), 17-25$.

Krisnanda, P. H., \& Surya, I. B. K. (2019). Effect of emotional and spiritual intelligence on transformational leadership and impact on employee performance. International Research Journal of Management, IT and Social Sciences, 6(3), 70-82.

Sudirman, A., Lie, D., Sherly, S., \& Dharma, E. (2019). The Impact of Work Discipline and Work Ethic on the Teacher Performance of Sultan Agung Pematangsiantar Private Middle School Teachers TA 2018/2019. International Journal of Business Studies, 3(3), 125-135.

Manik, E. (2016). The influence of transformational leadership on achievement motivation and organizational climate and employee performance. International Journal of Academic Research in Business and Social Sciences, 6(12), 599-608.

Matin \& Fuad, N. (2016). Manajemen Sarana dan Prasarana Pendidikan: Konsep dan Aplikasinya. Jakarta: Raja Grafindo Persada. 
Mavhungu, D., \& Bussin, M. H. (2017). The mediation role of motivation between leadership and public sector performance. SA Journal of Human Resource Management, 15(1), 1-11.

Money, V. (2017). Effectiveness of Transformational Leadership Style in Secondary Schools in Nigeria. Journal of Education and Practice, 8(9), 135-140.

Mukhtar. (2015). Strategi Kepala Sekolah dalam meningkatkan kinerja guru pada SMP Negeri di Kecamatan Masjid Raya Kabupaten Aceh Besar. Jurnal Magister Administrasi Pendidikan Universitas Syiah Kuala, 3(3), 103-117.

Peraturan Menteri Pendidikan Nasional Republik Indonesia Nomor 13 tahun 2007 tentang Standar Kepala Sekolah/ Madrasah. Jakarta: Depdiknas.

Peraturan Pemerintah Nomor 19 Tahun 2005 tentang Standar Nasional Pendidikan Bab VII Pasal 42. Jakarta: $x x x$.

Rafferty, A. E., \& Griffin, M. A. (2004). Dimensions of transformational leadership: Conceptual and empirical extensions. The Leadership Quarterly, 15(3), 329-354.

Robbins, S., \& Timothy A, J. (2010). Perilaku Organisasi. Edisi ke-16.. Jakarta: Salemba Empat.

Salam, B., Ma'ufur, M., \& Laeli, S. (2017). Pengaruh Budaya Kerja terhadap Kinerja Guru Bersertifikasi di Madrasah Aliyah. Tadbir Muwahhid, 1(1), 32-42.

Schmitt, A., Den Hartog, D. N., \& Belschak, F. D. (2016). Transformational leadership and proactive work behaviour: A moderated mediation model including work engagement and job strain. Journal of Occupational and Organizational Psychology, 89(3), 588-610.

Septyan, F. B., Al Musadieq, M., \& Mukzam, M. D. (2017). Pengaruh gaya kepemimpinan transformasional terhadap motivasi dan kinerja (Studi Pada Karyawan CV. Jade Indopratama Malang). Jurnal Administrasi Bisnis, 53(1), 81-88.

Sinaga, H. G., Asmawi, M., Madhakomala, R., \& Suratman, A. (2018). Effect of change in management, organizational culture and transformational leadership on employee performance PT. Adhya Tirta Batam. International Review of Management and Marketing, 8(6), 15-23.

Singarimbun, M., \& Effendi, S. (2003). Metode Penelitian Survey. Cetakan ke-2. Jakarta: Pustaka LP3ES Indonesia.

Suhelayanti, Aziz, M. R., Sari, D. C., Safitri, M., Saputra, S., Purba, S., Revida, E., Purba, R. A., Muharlisiani, L.T., \& Simarmata, J. (2020). Manajemen Pendidikan. Medan: Yayasan Kita Menulis.

Suranto. (2019). Inovasi Manajemen Pendidikan di Sekolah: Kiat Jitu Mewujudkan Sekolah Nyaman Belajar. Surakarta: Oase Group.

Usman, N., \& Murniati. (2019). Pengantar Manajemen Pendidikan. Serang: An1mage.

Wahyuningsih, U., Faizah, N., \& Agustin, N. H. (2018). Budaya Kerja Direktorat Pembinaan SMA. Jakarta: Direktorat Pembinaan SMA.

Wang, G., Oh, I.-S., Courtright, S. H., \& Colbert, A. E. (2011). Transformational leadership and performance across criteria and levels: A meta-analytic review of 25 years of research. Group and Organization Management, 36(2), 223-270.

Yuki, G. (2010). Kepemimpinan dalam Organisasi. Edisi Kelima. Jakarta: Indeks. 